\title{
Dos
}

\section{¿Dónde y con quién comienza la ética digital?}

DOI: 10.29236/sistemas.n153a7

\section{Resumen}

La posibilidad de construir una ética para lo digital en nuestra sociedad implica partir de una premisa: la autonomía como expresión de la libertad de decisión y la inteligencia como mecanismo de relación donde se deben conjugar actores, escenarios y saberes que permitan dar sentido a principios de justicia, sostenibilidad, precaución y responsabilidad.

\section{Palabras Claves}

Ética, digital, tecnología, generaciones, Inteligencia Artificial.

\section{Jaime Durán García}

\section{Introducción}

La utopía de salvaguardar los principios éticos en tiempos de cambios tecnológicos es un imperativo generacional para enfrentar la complejidad del tiempo histórico y moral respecto a los problemas de la técnica, la tecnología y la inge-

niería; para ello, el manejo de la ética permitirá abrir un aprendizaje de oportunidades, pero también tomar en cuenta los riesgos que los sistemas artificiales producen, situación que nos invita a reflexionar de manera profunda sobre los impactos colaterales en los comportamien- 
tos humanos y la manera en que surgirán los cambios culturales y sociales; lo digital, además de utilizar la metáfora de la "nube" viene permeando expresiones de moda para hablar de internet como espacio de comunicación y de oportunidades. Pensar en la ética digital es buscar de manera simple como interpretar el código social para solucionar los problemas de Internet y sus aplicaciones que la legislación no puede resolver.

Todo progreso en tecnología será siempre una bendición para las mentes que actúan con criterios de bienestar y de búsqueda del bien, pero una situación contradictoria para las personas que actúan de manera repetitiva y sin horizontes de convivencialidad. Debido a ello, uno de los grandes dilemas éticos en el uso de tecnología para campos como el de la mecatrónica viene en relación con su empleo en temas de comunicación entre las cosas, seguridad, tanto en beneficio de la ciudadanía como en el mal manejo de las armas por parte de las autoridades del orden como de grupos al margen de la ley. Temas que son nuevo punto de interés, los drones y la venta de software de reconocimiento facial. Así las cosas, el ingeniero debe convertirse en un actor fundamental dentro de los procesos de creación e innovación para un mundo cada vez más complejo, por lo cual no debe perder la identidad humana ni caer ante la tentación de los beneficios del corto plazo.
El compromiso de la ingeniería

El trabajo de la ingeniería ha sufrido una alteración sustancial en su rol acostumbrado a dominar la naturaleza y los ritmos de producción, a través del diseño, calidad, precisión y productividad, entre otros aspectos y hoy se enfrenta a los asuntos propios de la era digital. Los programas de ingeniería en el marco de los valores y en especial de los impactos de la digitalización deben ajustarse a las necesidades de formación y actualización tecnológica, de cara a los retos del cambio exponencial tales como: la convergencia, la producción de contenidos digitales, el cambio en las rutinas para el logro de competitividad, las nuevas plataformas y la irrupción de intereses cognitivos más dinámicos en el espacio mediático.

La formación integral, equilibrada entre lo técnico instrumental y lo ético digital, debe ofrecer a los actores dos posibles rutas de formación: la vertiente profesional y la del compromiso social. En el libro "Industrias que piensan", se comenta que los designios tecnológicos que mueven el futuro industrial, como es el caso de las industrias 4.0, no se deben hacer solo con incrementos de competitividad, productividad e innovaciones tecnológicas, sino también con conocimientos sociales (Gurrutxaga \& Galarraga, 2018, pág. 13), lo que exige una interpretación ética.

Aunque la mirada ética tiene un importante componente reflexivo so- 
bre la modernidad tecnológica, los desarrollos en algunas de las sociedades "avanzadas" comienzan a desdibujar responsabilidades humanas al haber incorporado una serie de características propias de la inteligencia humana, que conviene tener presentes en la formación profesional de nuestros países a la hora de analizar reflexivamente los impactos reales producidos por las nuevas tecnologías digitales en nuestra cultura.

\section{La era digital}

La era digital, implica la creación de una comunidad de personas que desarrolle elementos respetuosos con el contexto, en el marco de una identidad de acción entre la inteligencia humana y la artificial, pues esta última, a pesar de ser desarrollada con fines de bienestar, se soporta en el afán desmesurado de dar propiedades de comunicación entre cosas y elementos desarrollados sobre un supuesto de confort, para que actúen con un cierto grado de autonomía.

Al convertirse internet en un instrumento esencial de trabajo, de acceso al conocimiento, de productividad e igualdad por la fluidez e interconectividad, se debe garantizar la existencia de elementos que no alteren la esencia de la cultura y la actividad humana. Desde esta perspectiva, la ética digital permite comenzar a generar un concepto para considerar las situaciones y los procesos sociales, como una construcción en permanente cam- bio. Ala manera de Bauman (2016), una ética para una modernidad líquida, donde lo estático comienza a desaparecer y la fluidez del conocimiento se adapta a la cultura, se analiza la complejidad de las nuevas sociedades y la manera de enfrentar el fenómeno de la inmediatez, propio de la digitalización.

El cambio generacional, en el que no se generan fronteras, crea traslapos culturales que deben ser amparados en una ética basada en principios para orientar acciones que permitan formular una forma creativa encaminada a establecer puentes de convivencia entre máquinas y humanos, en la que el diálogo y la comprensión cognitiva faciliten una mejor relación entre las generaciones y los desarrollos tecnológicos. Hoy podemos dar cuenta de por lo menos cinco generaciones conviviendo, y si cada generación construye una ética radicalmente diferente para un contexto cambiante, no será posible conectar los principios fundamentales de bienestar, respeto, equidad y autonomía con los cambios sociales, culturales y tecnológicos y el código se apartará del marco del espectro ético, de manera que no se pueda garantizar un mínimo de bienestar humano y ambiental utilizando la regla: "no hagas a otros lo que no quieres que te hagan a ti".

Sin embargo, dado que las amenazas a la vida en todas sus manifestaciones están acompañadas de artefactos y equipos desarrollados 
con criterio de Inteligencia Artificial (IA), se puede dar paso a un espacio de la ética aplicada como es el caso de la bioética, garante del manejo de la digitalización planteada para un campo de trabajo bajo un marco valorativo de responsabilidad, sostenibilidad y precaución, con principios capaces de desarrollar acciones en los contextos tecnológicos y de la ingeniería. La era digital ha trazado una ruta de valores, lo que supone que la visión ética y bioética que las generaciones tienen del mundo, al ser distintas, han sido orientadas por unos patrones comunes que se albergan con un sello de utilidad, los cuales se convierten en fundamentos de momento, que llegan a superar las características específicas de una actuación humana, que en esencia debe responder a la búsqueda de los principios universales.

Si hoy la responsabilidad constituye un principio interpretativo desde el orden personal, profesional y social, éste debe dar cuenta de todos los actos humanos, por lo que la perspectiva digital debe orientarse también a responder por sus acciones y consecuencias, dando respuestas que garanticen el bienestar humano y de la vida en general. Como ha sido planteado porAlejandra Fierro en su libro "Ética y Juventud", gran parte de la complejidad que enfrenta la ética hoy tiene que ver con la convivencia de cinco generaciones en una sola época (Fierro, 2018). A pesar de que la velocidad de los saltos tecnológicos en la era digital promueve un pensamiento diferente, la ética digital como saber práctico que se reinventa todos los días debe crear y sostener criterios para entender lo bueno y lo malo; por lo tanto, serán necesarios más momentos de reflexión para superar los intereses de la celeridad tecnológica, de manera que se despierte la voz interior que, sin dar certezas, sí reaccione ante la necesidad de crear un bienestar en la vida.

Para entender la era digital, la utopía del bienestar sobre la vida debe estar presente, pues se convierte en uno de los lenguajes visibles de la ética, al permitir cuestionar y actuar sobre los alcances de la cultura digital. Lograr que un artefacto o un equipo electrónico haga algo, no significa que dicha máquina pueda pensar. Para ello, "La ética de la inteligencia Artificial necesita de muchas voces: empresarios, obreros, escritores, científicos, gente mayor, gente joven, juristas, tecnólogos, artistas, ingenieros, periodistas, todos, porque todos sin excepción vamos a convivir con ella", (Latorre, 2019, pág. 18). De donde puede verse que, al existir una gran capacidad de almacenamiento, rapidez en el procesamiento y algoritmos de decisión sofisticados, la ética logra conjugar otras variables de contexto que las máquinas no logran identificar.

\section{Ética para la era digital}

En la era digital la ética acompaña a los seres humanos conscientes y 
honestos para vivir la dinámica de transformación y de cambio, pero, en la actualidad, se observa que muchas personas se refieren a la Inteligencia Artificial -IA-, como una consecuencia del progreso sin saber exactamente en qué consiste. Esto merece hacer un llamado permanente para mantenerse activos en la realización del potencial humano, puesto que la IA debe convertirse en complemento y no en sustituto del actuar; tal es el caso del uso de sensores electrónicos que, bajo la metáfora de los sentidos, copian las condiciones de la inteligencia humana y replican acciones propias de la capacidad cognitiva de los seres vivientes.

En la era digital, el ser humano no puede esclavizarse a la tecnología dejando de lado el interés por el otro, en su condición de respeto y garantía de bienestar; debe seguir obedeciendo a su razón intrínseca de generar el bien colectivo, de la forma como Restrepo propone en su interpretación a Sartre, inspirado por Kant, que la libertad es ese poder de elegir y decidir sobre cuál es el rol y la textura de nuestro propio ser (Restrepo, 2018, pág. 16). En este contexto, el espectro de la ética digital se puede extender a actores dotados de autonomía e inteligencia que escogen cursos de acción en forma libre; por tanto, pensar en dicha propuesta, implicaría desarrollar un algoritmo de gran complejidad, que permita dar respuestas a la forma como la capacidad inteligente del ser humano actual desarrolla condiciones específicas.

Desde el punto de vista de la ética $y$, en especial de la ética digital, habrá decisiones que puedan ser automatizadas, pero no autónomas, pues, hasta hoy, no resulta posible desarrollar máquinas con inteligencia general; por ello, es imprescindible que exista un compromiso fundado en principios, en todas aquellas personas que desarrollan algoritmos cognitivos para la toma de decisiones.

Para Adela Cortina, la ética es un encuentro sinérgico producto de la justicia y de la felicidad, toda vez que son los horizontes que requieren un esfuerzo humano para su articulación (Cortina, 2016). Si a ello se le agrega lo digital, se debe integrar una corresponsabilidad, en la que los actores de las cinco generaciones que hoy conviven, deben tomar los elementos de sus contextos sociales y culturales para desarrollar, a través de una propuesta principialista, la ruta que interprete las responsabilidades y el respeto de toda manifestación de vida. De esa manera se pueden incorporar los descubrimientos científicos y las innovaciones tecnológicas en momentos de transformación tecnológica, bajo una interpretación humana que no podrá ser sustituida por las máquinas.

Por lo tanto, la ética digital debe comenzar con la aceptación de un modelo teórico que proponga una 
concepción posnatural de la naturaleza, como construcción social. Eso hará que se trasladen las decisiones y reflexiones hacia modelos algorítmicos que integren nuevas variables de manera que resistan la miopía de la interpretación humana. De esta manera, se dará un marco único que reúna las interpretaciones y transformaciones, que han estado siempre presentes en el mundo que habitamos.

Los llamados nativos digitales, serán los invitados a un nuevo protagonismo humano sobre la idea de lo digital y su reflexión deberá estar en convergencia con esta nueva época geológica: el antropoceno. De esa manera, la ética digital responderá a la fusión entre el capital natural con el capital digital, sustentada por acciones deliberadas de la actividad humana. Eso garantizará seguir actuando en función de las necesidades morales para la transformación de la naturaleza.

\section{Referencias}

Bauman, Z. (2016). Modernidad Líquida. Madrid: Fondo de cultura Económica.

Cortina, A. (2016). ¿Para qué sirve realmente ...? La ética. Bogotá: Editorial Planeta Colombia.

Fierro, A. (2018). Ética y juventud: Los retos éticos de las nuevas generaciones. Bogotá: Ediciones Aurora.

Gurrutxaga, A., \& Galarraga, A. (2018). Industrias que piensan. Madrid: Catarata.

Latorre, J. (2019). Ética para máquinas. Bogotá: Editorial Planeta Colombiana.

Restrepo, J. (2018). La constelación Ética. Cartagena: Fundación Gabriel García Márquez.

Jaime Durán G. Ingeniero Civil, especialista en Bioética, Docencia Universitaria y Gerencia de Tecnología. Magíster en Educación y candidato a Doctor en Educación. Decano de Ingeniería Mecatrónica, Universidad Piloto de Colombia. Director de la Red de Programas de Ingeniería Mecatrónica y Automatización RIMA. Miembro ACIEM en las comisiones de Ética y Formación e Integración Profesional. 